\title{
IMAGINAÇÃO: ENTRE O MEDO E A LIBERDADE
}

Daniel C. Avila*

Resumo: Medo e esperança aparecem na história da filosofia como problemas situados na dimensão temporal da existência. Espinosa acompanha essa tradição, bem como o uso da filosofia como uma medicina animi, porém reserva para si algumas diferenças. Ressaltando o papel da imagem na constituição de medo e esperança, demarca a via pela qual estes dois afetos são necessariamente produzidos pela limitação da imaginação à duração dos corpos. No entanto, quando livre dos impedimentos à sua potência, a mente é capaz de ordenar e concatenar as afecções do corpo, considerando a si mesma sem relação ao corpo, sob uma nova perspectiva. O tratamento do problema do medo, portanto, não se localiza no tempo presente, mas sim na eternidade.

Palavras-Chave: Benedictus de Espinosa, esperança, medo, imaginação, liberdade.

Mostre-me um homem que não é um escravo; um é escravo do sexo, outro do dinheiro, outro da ambição; todos são escravos da esperança ou do medo (Sêneca 4, Ep. 47, p. 95)

Em uma imagem poética que Sêneca emprega na carta $\mathrm{V}$ da correspondência mantida com Lucílio, esperança e medo marcham “juntas, como um prisioneiro e a escolta à qual se prendem suas algemas" (Sêneca 4, Ep. 5, p. 38). Mas ainda que a afinidade íntima entre esses afetos possa ser considerada fonte de temor a um aprendizado ético, o estóico prescreve

* Mestrando em Psicologia Escolar e do Desenvolvimento Humano - Instituto de Psicologia -

Universidade de São Paulo. 
uma solução, tomando emprestado um escrito de Hecato: "'Deixe de ter esperança', ele diz, 'e você deixará de ter medo"' (idem).

Para o estóico romano, medo e esperança, assim como as outras paixões, seriam doenças das quais o homem deve ser curado. Mas como a medicina, enquanto técnica do bom funcionamento do corpo, não alcançasse em seu ofício tal empresa, à filosofia é feita a convocação a agir sob a forma de uma terapia, sob as vestes de uma medicina animi. $\mathrm{O}$ exame filosófico que apresenta Sêneca é que medo e esperança

pertencem a uma mente em suspense, a uma mente em estado de ansiedade por mirar sempre o futuro. Ambos são devidos principalmente à projeção de nossos pensamentos além de nós mesmos em lugar de nos adaptarmos ao presente. É assim que a previsão, a maior benção que foi dada à humanidade, é transformada em maldição. Animais selvagens fogem dos perigos que realmente vêem e, uma vez que tenham escapado, não mais se preocupam. Nós, entretanto, somos atormentados de maneira idêntica pelo que já aconteceu e o que irá acontecer. Um número de bênçãos fazem-nos mal, pois a memória traz de volta a agonia do medo enquanto a previsão a traz prematuramente. Ninguém confina sua tristeza ao presente (idem).

Sêneca demarca, portanto, o problema do medo e da esperança na dimensão temporal da existência. São paixões que afetam o homem em um descompasso cognitivo envolvido em conflitos com presente, que o assolam de tal maneira que ele pode apenas recorrer ao deslocamento dos seus mecanismos imaginários a instantes transcendentes, refugiando-se em outro tempo. Tal atividade patológica da imaginação torna possível que um medo futuro seja tão ameaçador quanto um já passado, e por isso ela deve ser o centro do tratamento. Pois, reduzida a potência de prever a esse uso, o homem se depara com uma situação completamente desfavorável, até mesmo se comparado com os animais, sem encontrar em tempo algum qualquer paz. Por outro lado, a constituição de um modo de vida correto, curado das paixões nocivas, é possível a partir de um aprendizado ético que, por uma educação da imaginação, combatendo sua ignorância, retorne ao tempo atual. No diagnóstico final de Sêneca, apenas encontrando no presente sua força de agir e existir é que o homem pode exercer um bom uso de suas faculdades projetivas, em prol de uma vida plena e feliz.

Aquestãodomedoedaesperançanafilosofia de Espinosa estabelecese, em uma primeira aproximação, sobre as mesmas considerações que são abordadas por Sêneca. Assim por exemplo, Espinosa afirma que o "medo é uma tristeza e, já que a esperança não existe sem o medo, ela também não tem nada em si que a faça útil ao homem" (Spinoza 5, E V, P47 dem, p. 324). Isso não significa que, para Espinosa, medo e esperança sejam necessariamente maus ao homem, dado que o medo pode ser utilmente empregado na supressão de uma alegria excessiva, assim como a esperança pode evitar o desespero quando se imagina algo que exclui a idéia de algo que certamente causaria mal no futuro. A utilidade de ambos afetos, no entanto, é indireta e não depende deles em si. Não obstante, o medo e, sobretudo a esperança, adquirem um papel fundamental na constituição da melhor forma que pode adotar um regime qualquer, tema exposto no Tratado Político, porém que escapa do escopo do atual trabalho.

Da mesma maneira que Sêneca, Espinosa também acredita que medo e esperança são afetos que se originam a partir de uma disposição inadequada da imaginação, atrelada a uma temporalidade transcendente isto é, uma temporalidade dada na imaginação e que está para além do presente atual, indo em direção ao passado ou ao futuro: "a esperança nada mais é do que uma alegria instável, surgida da imagem de uma coisa futura ou passada de cuja realização temos dúvida. O medo, por outro lado, é uma 
tristeza instável, surgida igualmente da imagem de uma coisa duvidosa" (Spinoza 5, E III P18 esc 2, p. 187). Espinosa também afirma que o problema da esperança e do medo deve ser resolvido em uma dimensão cognitiva, pois são afetos que indicam uma carência de conhecimento e uma impotência da mente. Conseqüentemente, quanto mais o homem se esforça em viver sob a condução da razão, tanto menos depende da esperança e se livra do medo.

Apesar dos pontos comuns, a chave para compreender a solução proposta por Espinosa como tratamento está localizada em uma outra dimensão temporal. Para Sêneca, como vimos, o homem livre do medo e da esperança vive voltado para o presente, enquanto que para Espinosa, a estratégia para esse combate é "dominar, o quanto pudermos, o acaso; e por dirigir nossas ações de acordo com o conselho seguro da razão" (Spinoza 5, E IV, P47 esc, p. 321). Trata-se, na visão espinosana, não apenas de viver o presente, mas de confrontar a ordem comum da natureza, com seus encontros fortuitos que produzem um conhecimento confuso e mutilado, e submetê-la ao império da razão, do conhecimento claro e distinto. Mais ainda, trata-se de operar um esforço para que a mente seja internamente determinada e possa compreender a si mesma, a Deus e às coisas, sob um aspecto de eternidade, em sua maior parte com relação à parte sua cuja determinação é externa e acompanhada da impotência cognitiva, efeito da imaginação orientada à transcendência.

Essa incrível potência da imaginação em representar, no tempo presente, afetos ligados ao passado e ao futuro, tem as suas causas necessárias explicadas na segunda parte da Ética, onde Espinosa dedica parte de seu texto à demonstração do modo de funcionamento da imaginação. De acordo com a proposição 17 dessa parte: "Se o corpo humano é afetado de uma maneira que envolve a natureza de algum corpo exterior, a mente humana considerará esse corpo exterior como existente em ato ou como algo que lhe está presente, até que o corpo seja afetado de um afeto que exclua a existência ou a presença desse corpo" (Spinoza 5, E II, P17, p. 111). Ainda que a idéia de uma coisa presente e existente seja diferente da idéia de uma coisa não presente, isto é, sobre a qual não se pode ter certeza sobre a sua existência, a força com que a imaginação pode fornecer explicações à mente sobre a realidade atual é a mesma com a qual ela torna presentes as imagens das coisas que já não estão à sua percepção. Assim, no escólio dessa proposição, Espinosa afirma que a diferença da idéia de Pedro, que constitui a mente do próprio Pedro, e a idéia desse mesmo Pedro que existe em outro homem (Paulo) é que a primeira explica a essência do corpo de Pedro e não envolve a existência senão enquanto Pedro existe, e a segunda indica mais o estado do corpo de Paulo (ou seja, a afecção cuja causa é o corpo de Pedro), que a natureza de Pedro. Assim, enquanto durar o estado do corpo de Paulo, sua mente considerará Pedro como lhe estando presente, mesmo que Pedro já não mais exista.

Após essa passagem, Espinosa define a noção de imagem: "as afecções do corpo humano, cujas idéias nos representam os corpos exteriores como estando presentes, embora elas não restituam as figuras das coisas" (Spinoza 5, E II, P17 esc, p. 111), o que anuncia uma verdadeira liberdade da mente quando esta despreza o erro da faculdade de imaginar e a supera como fonte única de conhecimento. De fato,

a mente não erra por imaginar, mas apenas enquanto é considerada como privada da idéia que exclui a existência das coisas inexistentes como se lhe estando presentes. Pois, se a mente, quando imagina coisas inexistentes como se lhe estivessem presentes, soubesse, ao mesmo tempo, que essas coisas realmente não existem, ela certamente atribuiria essa potência de imaginar não a um defeito de sua natureza, mas a uma virtude, sobretudo se essa faculdade de imaginar dependesse exclusivamente de sua natureza, isto é, se ela fosse livre (idem). 
A causa necessária, portanto, que determina que a mente seja afetada de maneira idêntica pelas imagens de uma coisa presente e de outra não presente é a servidão da imaginação à duração. Ora, sendo determinada pela ordem comum da natureza e pela presença e ausência das coisas, a mente despreparada pode apenas imaginar a sua existência, afastando de seu julgamento suas respectivas durações. Espinosa alerta o leitor da Ética para o perigo que emana de tal propriedade da imaginação, afirmando nas proposições 30 e 31 que da duração do nosso corpo e das coisas singulares que nos são exteriores não se pode ter senão um conhecimento extremamente inadequado. Isso se dá, como ele demonstra, porque a duração de um corpo não depende de sua essência (pelo axioma 1 dessa parte) nem da natureza absoluta de Deus (pela proposição 21 da primeira parte). A duração do corpo e das coisas singulares depende apenas da ordem comum da natureza e do estado das coisas, de modo que a idéia imaginativa a respeito da duração desses corpos é inadequada por não se referir à sua essência nem à natureza de Deus e, assim, não permite considerar as idéias que não têm como objeto este corpo.

Em contraposição à força com a qual a idéia referida à duração exprime a extrema inadequação da imaginação, Espinosa apresenta a idéia clara e distinta do conhecimento adequado, necessariamente existente em Deus visto que ele, em seu intelecto divino, possui as idéias do corpo humano e de todas as outras coisas. A forma adequada de conhecer a realidade é, portanto, aquela que parte da idéia que "a mente humana é uma parte do intelecto infinito de Deus" (Spinoza 5, E II, P11, p. 95) para apreender o conhecimento da duração do corpo em Deus, isto é, para além da ordem comum da natureza e dos estados de corpo, referindo-o à sua essência e à natureza de Deus.

O arremate de tal denúncia é apresentado no corolário da proposição 31 dessa parte, quando Espinosa, por meio da afirmação de que todas as coisas particulares são experimentadas como contingentes e corruptíveis, deduz que não se pode ter delas, em sua duração, qualquer conhecimento adequado. E, como complementa o escólio da proposição 33, não há "nenhuma outra razão para se dizer que uma coisa é contingente, a não ser a deficiência de nosso conhecimento" (Spinoza 5, E I, P33 esc, p. 57). É o conhecimento inadequado, engendrado pelo binômio imaginaçãoduração, que explica, portanto, a potência da imaginação em persistir na representação de idéias transcendentes ao presente e, por esse mesmo caminho, a servidão ao medo e à esperança. Espinosa demonstra, assim, a via cognitiva pela qual estes dois afetos são necessariamente produzidos por uma imaginação limitada à duração. De maneira paradoxal, é como se o sujeito esperançoso ou medroso estivesse, como na definição de Sêneca, alienado de seu presente; contudo, ao mesmo tempo, esse apelo à transcendência deve ser compreendido como causado por uma “intoxicação” do presente, limitada à duração dos corpos.

É de se notar que o próprio Espinosa já se dava conta dos riscos que corria com tais afirmações, o que se verifica na digressão ao final de um escólio da segunda parte da Ética, no qual solicita que elas somente sejam julgadas quando o leitor tenha "lido tudo até o fim" (Spinoza, E II, P11 esc, p. 95). A razão de tal cautela se explica pela severidade com que esse pensamento, implicando a afirmação de uma ontologia do necessário, chocase com a tradição teológico-metafísica do possível (Chaui 1 e Chaui 3).

A corrente teológico-metafísica à qual Espinosa se contrapõe é aquela fundada sobre a oposição entre os binômios liberdade-vontade e necessidade-natureza, com a conseqüente localização de Deus no primeiro termo, associando-o à imagem de um agente que opera por vontade própria tendo um fim em vista. Tendo Deus criado o mundo porque quis - assim como poderia não tê-lo criado se assim o quisesse -, os seres singulares da Natureza são considerados como frutos de uma ação voluntária e, por isso, 
condenados a realizar aquilo que lhes é necessário e involuntário. Nessa oposição entre o reino da liberdade e o da necessidade, qualquer objeto de escolha é contingente, pois as leis da natureza só são necessárias na medida em que Deus teve essa vontade. E, assim, a tradição teológicometafísica conjuga liberdade e necessidade em uma seqüência causal, de modo que da vontade de Deus surge a necessidade da Natureza.

Contudo, quando esse pensamento se aplica no interior do campo político, a transcendência teológico-política transfere o direito de governar do monarca celeste ao monarca terrestre sob a égide da Teoria da Monarquia Absoluta. Trata-se da base da teocracia: o rei é soberano pela vontade de Deus - ou pela graça divina -, de quem recebe não só o poder, mas também as marcas que o tornam semelhantes ao monarca celeste. Este é uma pessoa transcendente ao universo, dotado de inteligência onisciente e vontade onipotente, criador do mundo a partir do nada, simplesmente por um ato contingente de sua vontade que assim o quis. Da mesma maneira, o monarca terrestre, escolhido de forma contingente pela vontade divina, inaugura o espaço social que está fora e acima da sociedade, depositando em sua vontade a força da lei (Chaui 1).

Desse modo, a metafísica se constitui enquanto ciência do possível na medida em que "seu objeto são os transcendentais segundo os quais se definem os universais como essências possíveis aptas à existência, que passam a existir por um ato da vontade divina criadora" (Chaui 1, p. 2). E a vinculação do desejo ao futuro, à falta, à ausência, isto é, a tudo aquilo que é considerado como possível, determina a servidão voluntária do homem. Inversamente, portanto, a filosofia espinosana trata de fundar uma ciência do necessário por meio de um conhecimento dos universais (isto é, as noções comuns) e das essências singulares que existem devido à necessidade absoluta de Deus. E, por fim, de exercer um vínculo do desejo à necessidade de uma potência plena, determinando-o por uma livre necessidade.
Essa vinculação é possível na medida em que a mente age, isto é, em que se converte em causa total dos afetos. Pois a mente interiormente disposta torna-se a causa adequada do conhecimento de si, de Deus e das coisas, constituindo a via cognitiva (isto é, por meio do conhecimento) à liberdade. E, nessa nova perspectiva, a mente funda uma nova relação com a eternidade ontológica.

O conhecimento em estado de servidão à duração do corpo e das coisas singulares é um conhecimento inadequado por não se referir à sua essência nem à natureza de Deus. Por outro lado, como Espinosa afirma na proposição 38 da parte II: “Aqueles elementos que são comuns a todas as coisas, e que existem igualmente na parte e no todo, não podem ser concebidos senão adequadamente" (Spinoza E II, P38, p. 129). Essa é uma proposição importante à epistemologia espinosana na medida em que é nela, e mais ainda na exposição de seu corolário, que Espinosa afirma a existência de idéias ou noções comuns a todos os homens, dado que todos os corpos estão em concordância quanto a certos elementos presentes no todo e nas partes, os quais devem ser percebidos por todos adequadamente, ou seja, clara e distintamente.

O critério que define tal adequação é apresentado posteriormente, na proposição 40: "Todas as idéias que, na mente, se seguem de idéias que nela são adequadas, são igualmente adequadas" (Spinoza E II, P40, p. 133). Assim, as idéias que são causadas pela essência da mente, e não mais originárias da imagem corporal das afecções, são idéias adequadas, e causa das noções comuns que constituem os fundamentos da capacidade humana de raciocínio. Espinosa agrega a essa afirmação, no segundo escólio da proposição, uma discussão sobre a formação dos conceitos universais transcendentais. A elaboração de seu argumento é a explicação, já apresentada no escólio da proposição 17 , de tal formação por sua causa necessária, a saber, a limitação do corpo humano em formar em si próprio, 
distinta e simultaneamente, apenas um número preciso de imagens, sendo incapaz de apreender a imagem de muitas coisas singulares. E a própria dedução do universal transcendental é efeito de tal limitação, pois no "momento em que as imagens se confundem inteiramente no corpo, a mente imaginará todos os corpos também confusamente e sem qualquer distinção, agrupando-os, como se de um único atributo se tratasse, a saber, o atributo de ente, coisa, etc" (Spinoza E II, P17 esc, p. 109).

O exemplo dado por Espinosa para demonstrar a constituição dos universais transcendentais é o da formação do conceito de homem. Assim, por se formarem, simultaneamente no corpo humano, um número de imagens de homens que supera a capacidade de imaginar, a mente se torna incapaz de imaginar as pequenas diferenças singulares como, por exemplo, a cor, o tamanho etc., de cada um. Desse estado, a mente é capaz apenas de imaginar aquilo que, em todos os homens - conquanto o corpo é por eles afetado -, está em concordância. Essa afecção mais comum no conjunto das imagens dos homens que se formaram no corpo é exatamente aquela que, por intermédio de cada indivíduo, mais afetou esse corpo. $\mathrm{E}$ é esse algo, em que todos os homens estão em concordância, que a mente exprime pelo nome de homem, formando o conceito que designa uma multiplicidade de coisas singulares.

Espinosa alerta, entretanto, que essas noções não são formadas por todos os homens da mesma maneira. Tudo depende da razão da coisa pela qual o corpo foi mais vezes afetado, e a razão pela qual a mente imagina ou lembra mais facilmente. Assim, os que admiram a estatura do homem associarão à palavra homem um animal de estatura ereta, outros, acostumados a outro aspecto, formarão dos homens uma outra imagem comum: um animal que ri, um bípede sem penas, um animal racional etc. "E, assim, cada um, de acordo com a disposição do seu corpo, formará imagens universais das outras coisas" (Spinoza, E II, P40 esc 2, p. 133).
Dada a multiplicidade de disposições dos corpos que formam imagens de homens, tais corpos entram em descordo sobre qual é o conceito possível e certo. Como Espinosa completa, não se deve surpreender-se pelo fato de "que dentre os filósofos que pretenderam explicar as coisas naturais exclusivamente pelas imagens dessas coisas, tenham surgido tantas controvérsias" (idem). A invenção de Espinosa está, portanto, na fundação de uma nova forma de conhecimento, baseada nos universais imanentes formados pela mente a partir de elementos reais e concretos, presentes ao mesmo tempo nas partes e no todo, assim como nas relações entre as partes e das partes com o todo. As noções comuns, justamente por isso, são igualmente compartilhadas por todos os homens, independentemente do estado de seus corpos e dos corpos exteriores.

No mesmo escólio, são apresentadas três maneiras de formar noções universais. A primeira maneira se dá a partir de coisas singulares, representadas mutilada e confusamente pelos sentidos do corpo, sem a ordem própria do intelecto. Como demonstra a proposição 29 da segunda parte, a idéia de uma afecção do corpo humano não envolve o conhecimento adequado do próprio corpo e, por não exprimir sua natureza está em discordância com a mente, isto é, consiste em uma idéia inadequada. A tais percepções, Espinosa dá o nome de conhecimento originado da experiência errática, pois sempre que a mente humana percebe as coisas segundo a ordem comum da natureza e por meio das idéias das afecções, ela não tem, de si própria, nem de seu corpo, nem dos corpos exteriores, um conhecimento adequado, mas apenas um conhecimento confuso e mutilado.

Afirmo expressamente que a mente não tem, de si própria, nem de seu corpo, nem dos corpos exteriores, um conhecimento adequado, mas apenas um conhecimento confuso, sempre que percebe as coisas segundo a ordem comum da natureza, isto é, sempre que está exteriormente determinada, pelo encontro fortuito com as coisas, a 
considerar isto ou aquilo. E não quando está interiormente determinada, por considerar muitas coisas ao mesmo tempo, a compreender suas concordâncias, diferenças e oposições (Spinoza, E II, P29 esc, p. 123)

Além do conhecimento originado da experiência errática, Espinosa agrega também a esse gênero o conhecimento a partir de signos: "por exemplo, por ter ouvido ou lido certas palavras, nós nos recordamos das coisas e delas formamos idéias semelhantes àquelas por meio das quais imaginamos as coisas" (Spinoza, E II, P40 esc 2, p. 135). De uma maneira geral, esse primeiro gênero de conhecimento tem como característica a determinação externa da mente por meio da idéia imaginativa inadequada. Em contraposição, quando a mente se encontra interiormente arranjada, as coisas são consideradas de forma clara e distinta de acordo com o segundo e o terceiro gênero de conhecimento.

O segundo gênero de conhecimento se caracteriza pelas noções comuns e as idéias adequadas das propriedades das coisas. Para demonstrar o modo de funcionamento desse gênero, Espinosa compara a resolução de um mesmo problema, efetuada por comerciantes e por um geômetra: "Sejam dados três números, com base nos quais quer se obter um quarto que esteja para o terceiro como o segundo está para o primeiro" (Spinoza, E II, P40 esc 2, p. 135). Os comerciantes, limitados ao primeiro gênero, não hesitam em multiplicar o segundo pelo terceiro e dividir o produto pelo primeiro, "ou porque não esqueceram ainda o que ouviram seu professor afirmá-lo, sem qualquer demonstração, ou porque experimentam-no, freqüentemente, com números mais simples" (idem). Já o geômetra resolve o problema por meio da demonstração da proposição 19 do livro 7 dos Elementos de Euclides, isto é, por causa da propriedade comum dos números proporcionais, empregando um conhecimento de segundo gênero.
Certamente, no caso de uma série de números simples, o cálculo do comerciante e o do geômetra têm como efeito o mesmo resultado. A diferença é que a explicação geométrica faz uso de uma propriedade comum à série numérica, isto é, a proporção ou razão, deduzida a partir da relação entre os dois primeiros números, na medida em que o comerciante apenas emprega operações com as quais já está se acostumou por meio do hábito. Para o primeiro existe uma idéia clara que envolve as idéias dos elementos singulares, enquanto que o segundo a ignora. Ainda que, no caso dos números simples, o conhecimento de primeiro e segundo gênero cheguem ao mesmo resultado, o mesmo não é valido para uma série de números complexos. Por outro lado, apesar da diferença entre os dois gêneros, quando aplicados a números simples, um não contradiz o outro, isto é, não há hierarquia entre os gêneros de conhecimento, no sentido de que um suprime, anula ou elimina o conhecimento obtido pela via de um outro. O que existe é uma diferença de potência, dado que um gênero pode mais ou menos que outro, em uma construção ativa da mente na qual os conhecimentos de distintos gêneros ocupam partes maiores ou menores da mente em uma situação de colaboração conjunta.

Uma das propriedades do conhecimento de segundo gênero é a de produzir as condições sob as quais a mente pode concatenar as afecções corporais em uma ordem própria à sua essência e, assim, determinar-se a si mesma. Isto ocorre porque, como mostra a proposição 10 da parte final da Ética: "Durante o tempo em que não estamos tomados por afetos que são contrários à nossa natureza, nós temos o poder de ordenar $\mathrm{e}$ concatenar as afecções do corpo segundo a ordem própria do intelecto" (Spinoza, E V, P10, p. 379). Justifica-se, assim, a necessidade humana por regras de vida que afastem da mente quaisquer afetos que sejam contrários à sua natureza (idéias inadequadas e afetos passivos), pois durante esse afastamento toda a sua potência pela qual se esforça em 
compreender a natureza das coisas não está impedida.

A idéia de potência da mente é explicada na proposição 26 da quarta parte da Ética: "Tudo aquilo pelo qual, em virtude da razão, nós nos esforçamos, não é senão compreender; e a mente, à medida que utiliza a razão, não julga ser-lhe útil senão aquilo que a conduz ao compreender" (Spinoza 5, E IV, P26, p. 293). De fato, a razão é o modo finito que compartilha absolutamente a essência da mente, pois a essência da razão não é senão a mente, à medida que compreende clara e distintamente (Spinoza 5, E IV, P26 dem, p. 293 - 295). De maneira inversa, em virtude da razão significa uma ação da mente em compreender clara e distintamente. Assim, não apenas a razão está em conformidade com a constituição ontológica da mente, mas também com o seu conatus, pois o “esforço por se conservar nada mais é do que a essência da própria coisa, a qual, à medida que existe como tal, é concebida como tendo força para perseverar no existir e para fazer aquilo que se segue, necessariamente, de sua dada natureza" (Spinoza, E IV, P26 dem, p. 293).

Da mesma maneira, um impedimento à potência da mente é uma idéia que, sem o ordenamento próprio da razão, apresenta-se como conhecimento inadequado e, assim, contradiz a natureza da mente. Tal contradição tem como efeito a diminuição da potência da mente em fazer aquilo que se segue de sua natureza, isto é, compreender clara e distintamente. Segue-se daí o critério que define se algo é bom ou mau, isto é, se algo nos leva efetivamente a compreender ou pode impedir que compreendamos. Porém, de que maneira pode-se fazer com que não sejamos facilmente mobilizados por estes afetos? Como chegamos a alcançar este ordenamento e concatenação racionais das afecções do corpo? Com efeito, dado que, como afirma a proposição 7 da quinta parte, quando se leva o tempo em consideração, isto é, a duração, os afetos que provêm da razão ou que ela suscita são mais potentes do que aqueles que estão referidos às coisas singulares que são consideradas como ausentes, exigindo-se, para refrear os afetos ordenados e concatenados segundo a ordem própria do intelecto, uma força maior do que a requerida para refrear os afetos imprecisos e erráticos.

Um aprendizado ético, enquanto não atinge um conhecimento adequado dos afetos, exige um princípio correto de viver, orientado por noções comuns. Essas regras seguras de vida, quando confiadas à memória e aplicadas continuamente aos casos particulares podem afetar continuamente a imaginação e, estando sempre à disposição na experiência cotidiana, tornam a mente, tanto quanto possível, afastada dos afetos que compõem um impedimento à sua potência.

Seguindo essa orientação, Espinosa deduz, no escólio da proposição 10 da quinta parte, o principio de que ódio deve ser combatido com amor em vez de ódio recíproco. Essa noção comum convém para que a razão esteja sempre à disposição dos homens, todas as vezes que se depararem com um encontro carregado de ódio. Ora, se um conhecimento inadequado poderia conduzir a uma reação de ódio igual ou mais forte nesse tipo de situação, com essa noção o homem passa a pensar e a refletir sobre as ofensas habituais dos outros e de si mesmo, bem como a maneira e a via pelas quais elas podem ser mais efetivamente rebatidas por meio da generosidade. Nesse caso ocorre que, no interior da imaginação, a imagem da ofensa está unida à imaginação dessa regra e, por isso, está sempre à sua disposição. Espinosa invoca, aqui, a proposição 18 da segunda parte da Ética, afirmando que se o corpo humano foi simultaneamente afetado por dois ou mais corpos, sempre que a mente imaginar um desses corpos, imediatamente se recordará também dos outros. A associação imaginativa pode ser, portanto, um mecanismo complementar à razão no que concerne à presença da noção comum ainda que no interior de uma experiência da contingência. Em seguida, Espinosa fornece um segundo exemplo e 
apresenta, sob o princípio da verdadeira utilidade, o bem que se segue da amizade mútua e da sociedade comum, e que a suprema satisfação do ânimo provém do princípio correto de viver, pois a satisfação consigo mesmo pode surgir apenas da razão e essa satisfação consigo mesmo é, na realidade, a maior coisa que se pode esperar (Spinoza 5, E IV P52 e seu esc, p. 325).

Um outro exemplo refere-se ao modo pelo qual "para acabar com o medo, é preciso pensar com firmeza, quer dizer, é preciso enumerar e imaginar, com freqüência, os perigos da vida e a melhor maneira de evitá-los e superá-los por meio da coragem e da fortaleza" (Spinoza 5, E V, P10, p. 380). Espinosa identifica o pensar com firmeza com a ação de imaginar perigos e a melhor maneira de evitá-los e superá-los. Para isso contribuem a coragem (animi praesentia), isto é, a presença ou força de ânimo, e a fortaleza (fortitudine). As definições de presença de ânimo e de fortaleza se encontram na terceira parte da Ética, quando Espinosa remete "todas as ações que se seguem dos afetos que estão relacionados à mente à medida que ela compreende, à fortaleza, que divido em firmeza $\mathrm{e}$ generosidade" (Spinoza 5, E III, P59 esc, p. 259). Assim, quando a mente age sob a fortaleza ela é a causa adequada de seus afetos. A fortaleza, assim como a razão, se encontra firmemente apoiada na afirmação do conatus, pois é definida pelo "desejo pelo qual cada um se esforça por conservar seu ser, pelo exclusivo ditame da razão" (Spinoza 5, E III, P59 esc, p. 259). A generosidade, por sua vez, é compreendida como o desejo pelo qual cada ser se esforça, pelo exclusivo ditame da razão, por ajudar os outros e para unir-se a eles por amizade. Chama a atenção o fato de Espinosa empregar de maneira reiterativa a expressão "pelo exclusivo ditame da razão" (ex solo rationis dictamine), como uma modalidade afetiva. De fato, existem diversas maneiras pelas quais o homem se esforça por conservar seu ser, todas elas agrupadas sob o conatus, assim como maneiras pelas quais ajuda os outros e se une a eles, porém nem todas elas são de fato reguladas pela razão. O exclusivo ditame da razão garante que a proposição 10 se encontre no âmbito do segundo gênero de conhecimento. A divisão da fortaleza em firmeza e generosidade se dá pelo contraste entre as ações que têm por objetivo a exclusiva vantagem do agente e aquelas que têm por objetivo também a vantagem de um outro, respectivamente. E, da mesma maneira, como completa este escólio, "a temperança, a sobriedade e a coragem diante do perigo, etc., são espécies de firmeza" (Spinoza 5, E III, P59 esc, p. 259).

A razão liberta o homem do medo e da esperança por meio do império sobre a fortuna. Ainda que a experiência da acaso, e a conseqüente paixão pelo possível, tenham causas absolutamente necessárias, trata-se de exercer, tanto quanto se pode, o domínio sobre a contingência. Não se trata, obviamente, de afirmar que a razão possa exercer um império sobre a ordem da natureza, mas sim de exercê-lo sobre si mesma, engendrando a determinação interna da mente. E Espinosa finaliza o escólio da proposição 10 concluindo a verdadeira importância do segundo gênero:

Assim, quem tenta regular seus afetos e apetites
exclusivamente por amor à liberdade, se esforçará, tanto
quanto puder, por conhecer as virtudes e as suas causas,
e por encher o ânimo do gáudio que nasce do verdadeiro
conhecimento delas e não, absolutamente, por considerar
os defeitos dos homens, nem por humilhá-los, nem por
se alegrar com uma falsa aparência de liberdade. Quem
observar com cuidado essas coisas (na verdade, elas não
são difíceis) e praticá-las poderá, em pouco tempo, dirigir
a maioria de suas ações sob o comando da razão (Spinoza
5, E V, P10 esc, p, 381)

Sendo essas regras seguras de vida pertencentes ao segundo gênero, tem-se que a moderação do medo e da esperança se dá por uma 
via cognitiva, isto é, pelo uso da razão. Pela disposição freqüente dessas normas comuns, a mente pode se encontrar internamente disposta a refletir sobre os medos singulares que se apresentam na vida cotidiana. De fato, como enuncia a proposição 28 dessa parte, o esforço ou o desejo por conhecer as coisas por meio do terceiro gênero de conhecimento não pode provir do primeiro, mas, sim, do segundo gênero de conhecimento, pois das idéias mutiladas e confusas do primeiro gênero, não se seguem idéias claras e distintas.

O conhecimento de segundo gênero demonstra-se, de fato, necessário para que se alcance um terceiro gênero de conhecimento, ao qual Espinosa dá o nome de ciência intuitiva. Trata-se do conhecimento obtido a partir da idéia adequada da essência formal de certos atributos de Deus para chegar ao conhecimento adequado da essência das coisas. Com relação ao tempo, a razão consiste no melhor remédio para moderar os afetos de medo e esperança, pois, segundo o escólio da proposição 44 da segunda parte da Ética, é da natureza da razão considerar as coisas como necessárias, não como contingentes e deve-se exclusivamente à imaginação que as coisas possam ser consideradas, quer com respeito ao passado, quer com respeito ao futuro, como contingentes.

Para demonstrar como se processa o mecanismo de associação imaginária, Espinosa propõe a seguinte cena: uma criança que avista Pedro de manhã, Paulo, ao meio-dia, e depois Simão à tarde, se no dia seguinte visse Pedro novamente de manhã, esperaria que Paulo aparecesse novamente ao meio-dia, e Simão à tarde. E, se visse Simão, à tarde, imaginaria que Pedro e Paulo haviam passado durante o dia. Porém, se em lugar de Simão, a mesma criança visse no dia seguinte Jacó passando à tarde, sua imaginação flutuaria entre as idéias dos dois, e consideraria ambos como dois futuros contingentes. E para todas as outras coisas em relação com um tempo passado ou com um tempo presente, haveria a mesma flutuação da imaginação, e tais coisas seriam consideradas contingentes. Espinosa já antecipa no segundo corolário dessa proposição, uma idéia que só encontrará seu pleno desenvolvimento na quinta parte: "É da natureza da razão perceber as coisas sob uma certa perspectiva de eternidade" (Spinoza 5, E II, P44 esc, p. 141).

É importante notar que o sujeito da cena proposta por Espinosa não é um homem, mas uma criança, agente que será retomado mais tarde como aquele que não tem conhecimento adequado de si mesmo, de Deus e das coisas.

Como os corpos humanos são capazes de muitas coisas, não há dúvida de que podem ser de uma natureza tal que estejam referidos a mentes que tenham um grande conhecimento de si mesmas e de Deus, e cuja maior parte, ou seja, cuja parte principal é eterna, e que, por isso, dificilmente temem a morte (...) E, de fato, aquele que, tal como um bebê ou uma criança, tem um corpo capaz de pouquíssimas coisas e é extremamente dependente das causas exteriores, tem uma mente que, considerada em si mesma, quase não possui consciência de si, nem de Deus, nem das coisas. Em troca, aquele que tem um corpo capaz de muitas coisas, tem uma mente que, considerada em si mesma, possui uma grande consciência de si, de Deus e das coisas (Spinoza 5, E V, P39 esc, p. 407)

O esforço do homem no sentido de sua liberdade é o de relacionarse de uma maneira plena com o tempo, isto é, encontrar a eternidade divina a partir da experiência da duração das coisas singulares. Trata-se de um exercício para que o corpo da infância se transforme, tanto quanto o permite a sua natureza e tanto quanto lhe seja conveniente, em um outro corpo, capaz de muitas coisas e referido a uma mente que tenha extrema consciência de si mesma, de Deus e das coisas "de tal maneira que tudo aquilo que esteja referido à sua memória ou à imaginação não 
tenha, em comparação com o seu intelecto, quase nenhuma importância" (Spinoza 5, E V, P39 esc, p. 407). Mas qual seria esta nova relação com o tempo, pela via da eternidade?

Até a quarta parte da Ética, Espinosa define o primeiro e único fundamento da virtude ou do princípio correto de viver como sendo a busca daquilo que é útil para si, segundo o corolário da proposição 22 e a proposição 24 da quarta parte. Porém, na proposição 41 da última parte, ele afirma que mesmo ignorando a eternidade da mente, o homem que se orienta pelo exclusivo ditame da razão chega à mesma conclusão e considera como primordiais todos os afetos referidos à firmeza e à generosidade.

O tema da duração da mente, ou a mente considerada sem relação ao corpo, aparece sob a forma de um enigma no texto da Ética ao final do largo escólio da proposição 20 da quinta parte. A explicação do enigma aparece somente na proposição 40, que afirma que a mente tanto mais é perfeita quanto age. Deste modo, a parte da mente que permanece, isto é, que é eterna, é o intelecto, pelo qual o homem exclusivamente age. Por outro lado, a parte da mente que Espinosa demonstra perecer é a própria imaginação, por meio da qual exclusivamente o homem padece. Pois embora a mente não possa imaginar nem se recordar das coisas passadas, senão enquanto dura o corpo, conforme a proposição 21 , há uma parte sua que não é destruída quando o corpo perece e, segundo o escólio da preposição 40, "fica evidente que a nossa mente, à medida que compreende, é um modo eterno do pensar" (Spinoza 5, E V, P40 esc, p. 407).

Espinosa não atribui à mente humana, portanto, nenhuma duração possível de ser definida pelo tempo senão enquanto exprime a idéia atual do corpo, isto é, enquanto dura o corpo. Porém, dado que a expressão da essência do corpo na mente é concebida pelo próprio intelecto de Deus, essa expressão é algo que pertence à essência da mente e é necessariamente eterno.
Essa idéia que exprime a essência do corpo sob a perspectiva da eternidade é, como dissemos, um modo definido do pensar, que pertence à essência da mente e que é necessariamente eterno. Não é possível, entretanto, que nos recordemos de ter existido antes do corpo, uma vez que não pode haver, nele, nenhum vestígio dessa existência, e que a eternidade não pode ser definida pelo tempo, nem ter, com este, qualquer relação. Apesar disso sentimos e experimentamos que somos eternos. Com efeito, a mente não sente menos aquelas coisas que ela concebe pela compreensão do que as que ela tem na memória. Pois, aos olhos da mente, com os quais ela vê e observa as coisas, são as próprias demonstrações. Assim, embora não nos recordemos de ter existido antes do corpo, sentimos, entretanto, que a nossa mente, enquanto envolve a essência do corpo sob a perspectiva da eternidade, é eterna, e que esta existência da nossa mente não pode ser definida pelo tempo, ou seja, não pode ser explicada pela duração. Portanto, pode-se dizer que a nossa mente dura e que a sua existência pode ser definida por um tempo preciso apenas à medida que envolve a existência atual do corpo; e, apenas sob essa condição, ela tem o poder de determinar a existência das coisas pelo tempo e de concebê-las segundo a duração (Spinoza 5, E V, P23 esc, p. 391)

A permanência de uma parte da alma resolve o aparente problema de um modo finito ser eterno. Mais ainda, lança as bases de um aprendizado ético contra o medo, por meio de uma educação da imaginação. A compreensão verdadeira e livre do tempo na filosofia de Espinosa não está, como vimos, no presente, mas no seio da eternidade. Contudo, para alcançar essa relação plena com a dimensão temporal, a mente necessita tornar-se, tanto quanto possível, internamente disposta. A condição de existência desse movimento afetivo e cognitivo, contudo, não se limita ao seguimento de regras e princípios de vida que estimulem 
a razão como um exercício do desejo para além da duração, do medo e da esperança. É o próprio exercício da potência de pensar, livre dos impedimentos que lhe constituem as idéias inadequadas e os afetos passivos, que permite à mente conceber o corpo, Deus e as coisas sob a perspectiva da eternidade. Pois, quando internamente disposta, a mente considera os demais modos como estritamente necessários, ao passo que quando é afetada pelo medo e pela esperança vincula-se à imaginação da contingência temporal do passado e do futuro.

Restaria agora perguntar-nos qual seria a relação mantida pelo homem, plenamente orientado pela razão, com o medo e a esperança. Ora, sabemos que o medo é e sempre será uma paixão, isto é, tem e terá causas externas necessárias. Além disso, tendo uma origem externa, o medo não nasce da ignorância nem é suprimido pelo saber da verdade, o que poderíamos também dizer da esperança. Suas causas necessárias decorrem da própria constituição finita do homem, desde sempre rodeado e envolvido por outras partes da natureza, cuja potência de longe supera a do seu conatus e, assim, constantemente o amedrontam e conduzem a imaginar formas de evitar a sua própria aniquilação. O certo é que um aprendizado ético de forma alguma se dirige à anulação desses afetos, assim como a ciência intuitiva não elimina o conhecimento de outros gêneros. Trata-se de um esforço para que a mente mantenha uma maior parte internamente determinada e guiada à eternidade comparada àquela cuja determinação é externa e acompanhada da impotência cognitiva, efeito da imaginação orientada à transcendência. Afinal, o que podemos esperar de uma compreensão livre e verdadeira do tempo, senão a fortaleza para enfrentar e conhecer nossos verdadeiros medos e esperanças?

\section{IMAGINATION: BETWEEN FEAR AND FREEDOM}

Abstract: Fear and hope appear in the history of Philosophy as problems located in temporal dimension of existence. Espinosa follows this tradition, as well as the use Philosophy as a medicina animi, but sets apart for himself some differences. Giving prominence to the role of image in fear and hope constitution, he delimits the way by which these affects are necessarily produced by the limitation of imagination to body duration. However, when freed of the impediments to its potency, the mind is able to ordinate and concatenate body affections, considering itself without relation to the body, under a new perspective. Fear problem treatment, therefore, is not in present time, but in eternity.

Keywords: Benedictus de Espinosa, hope, fear, imagination, freedom.

\section{REFERÊNCIAS BIBLIOGRÁFICAS:}

1. CHAUI, M. Espinosa: poder e liberdade. Filosofia política moderna. De Hobbes a Marx Boron, Atilio A. CLACSO, Consejo Latinoamericano de Ciencias Sociales; DCP-FFLCH, Departamento de Ciencias Politicas, Faculdade de Filosofia Letras e Ciencias Humanas, USP, Universidade de Sao Paulo. 2006. Disponível em http://bibliotecavirtual.clacso.org.ar/ar/libros/secret/ filopolmpt/06_chaui.pdf

2. __ Imperium ou moderatio? Cad. Hist. Fil. Ci., Campinas, Série 3, v. 12, n. 1-2, p. 9-43, jan.-dez. 2002.

3. _ O fim da metafísica do possível: Espinosa e a ontologia do necessário. Anotações para aula de Pós-Graduação em Filosofia. Universidade de São Paulo, 2009

4. SÊNECA, L. A. Letters from a Stoic: Epistulae morales ad Lucilium. Penguin Classics: Londres, 1969.

5. SPINOZA, B. Ética: demonstrada à maneira dos geômetras. Autêntica: Belo Horizonte, 2008. 